\title{
Capsule Commentary on Andrade et al., Clinical Benefit of American College of Chest Physicians versus European Society of Cardiology Guidelines for Stroke Prophylaxis in Atrial Fibrillation
}

\author{
Hafiz Hussain, MD \\ New York Hospital Queens, Flushing, NY, USA. \\ J Gen Intern Med 30(6):833 \\ DOI: $10.1007 / \mathrm{s} 11606-015-3262-1$ \\ (c) Society of General Internal Medicine 2015
}

\begin{abstract}
A trial Fibrillation (AF) is the most common sustained arrhythmia encountered in clinical practice, with increasing prevalence in the aging population. About 2.2 million patients in the United States and 4.5 million patients within the European Union have AF. ${ }^{1}$ The most feared and devastating complications of $\mathrm{AF}$ are thromboembolism and ischemic stroke. About $15-20 \%$ of patients suffering from AF develop strokes. ${ }^{2}$ In view of an aging population, the higher physiological propensity for bleeding in the elderly and the overwhelming issues of polypharmacy, the decision for the use of anticoagulation is critical.

Andrade et al. $^{3}$ compared the conflicting guidelines of anticoagulation (recommended by the European Society of Cardiology guidelines) versus no anticoagulation (recommended by the American College of Chest Physicians guidelines) in patients aged 65 to 74 years who had AF with a CHADS2 score of 0 and without any contraindication for anticoagulation using real-world outcomes of stroke, intracranial hemorrhages, and extracranial hemorrhages. They found no benefit for anticoagulation with a number needed to treat with warfarin to prevent one stroke of 333. This expansion of warfarin use would cause about 44 extracranial hemorrhages per 333 patients. Since $7 \%$ of these extracranial hemorrhages were fatal, expanding warfarin use would cause roughly three fatal extracranial hemorrhages per one ischemic stroke prevented. Adding anticoagulation to the regimen of this patient population using the European Society of Cardiology guidelines would lead to a $10 \%$ increase in the use of anticoagulation.

The most recent $\mathrm{ACC} / \mathrm{AHA}^{4}$ guidelines recommend using the CHA2DS2-VASc score in this particular patient group.
\end{abstract}

Patients with a score of 0 can omit antithrombotic therapy. Those with a score of 1 can receive either aspirin or no antithrombotic therapy. Prospectively, it will be interesting to see real-world outcomes using the CHA2DS2-VASc score, particularly the choice of anticoagulation versus aspirin based on the individual component of this score, as a select group of patients might benefit from aspirin more than anticoagulation depending on their comorbidities, and vice versa. Also, researchers should determine if novel anticoagulants with safer bleeding profiles will benefit this patient population in terms of stroke prevention.

Conflict of Interest: The author has no conflicts of interest with this article.

Corresponding Author: Hafiz Hussain, MD; New York Hospital Queens, Flushing, NY 11355, USA (e-mail: drhhafiz@gmail.com).

\section{REFERENCES}

1. Go AS, Hylek EM, Phillips KA, Chang Y, Henault LE, Selby JV, Singer DE. Prevalence of diagnosed atrial fibrillation in adults: national implications for rhythm management and stroke prevention: the AnTicoagulation and Risk Factors in Atrial Fibrillation (ATRIA) Study. JAMA. 2001;285(18):2370-5.

2. Hart RG, Halperin JL. Atrial fibrillation and Thromboembolism: a decade of progress in stroke prevention. Ann Intern Med. 1999;131:688-95.

3. Andrade AA, Li J, Radford MJ, Nilasena DS, Gage BF. Clinical Benefit of American College of Chest Physicians versus European Society of Cardiology Guidelines for Stroke Prophylaxis in Atrial Fibrillation. J Gen Intern Med. 2015. doi: 10.1007/s11606-015-3201-1.

4. January CT, Wann LS, Alpert JS, Calkins H, Cigarroa JE, Cleveland JC Jr, Conti JB, Ellinor PT, Ezekowitz MD, Field ME, Murray KT, Sacco RL, Stevenson WG, Tchou PJ, Tracy CM, Yancy CW. ACC/AHA Task Force Members. 2014 AHA/ACC/HRS guideline for the management of patients with atrial fibrillation: executive summary: a report of the American College of Cardiology/American Heart Association Task Force on practice guidelines and the Heart Rhythm Society. Circulation. 2014;130(23):2071-104.

Published online March 21, 2015 